\title{
Flexible pension take-up in social security
}

\author{
Yvonne Adema $a^{1,2} \cdot$ Jan Bonenkamp ${ }^{2,3}$. \\ Lex Meijdam ${ }^{2,4}$
}

(C) The Author(s) 2015. This article is published with open access at Springerlink.com

\begin{abstract}
This paper studies the redistribution and welfare effects of increasing the flexibility of individual pension take-up. We use an overlapping-generations model with Beveridgean pay-as-you-go pensions and heterogeneous individuals who differ in ability and lifespan. We find that introducing flexible pension take-up can induce a Pareto improvement when the initial pension scheme contains within-cohort redistribution and induces early retirement. Such a Pareto improving reform entails the application of uniform actuarial adjustment of pension entitlements based on average lifespan. Introducing actuarial non-neutrality that stimulates later retirement further improves such a flexibility reform.
\end{abstract}

Keywords Redistribution - Welfare - Retirement - Flexible pensions - Actuarial adjustment

JEL Classification $\mathrm{D} 61 \cdot \mathrm{H} 23 \cdot \mathrm{H} 55 \cdot \mathrm{J} 26$

Electronic supplementary material The online version of this article (doi:10.1007/s10797-015-9354-3) contains supplementary material, which is available to authorized users.

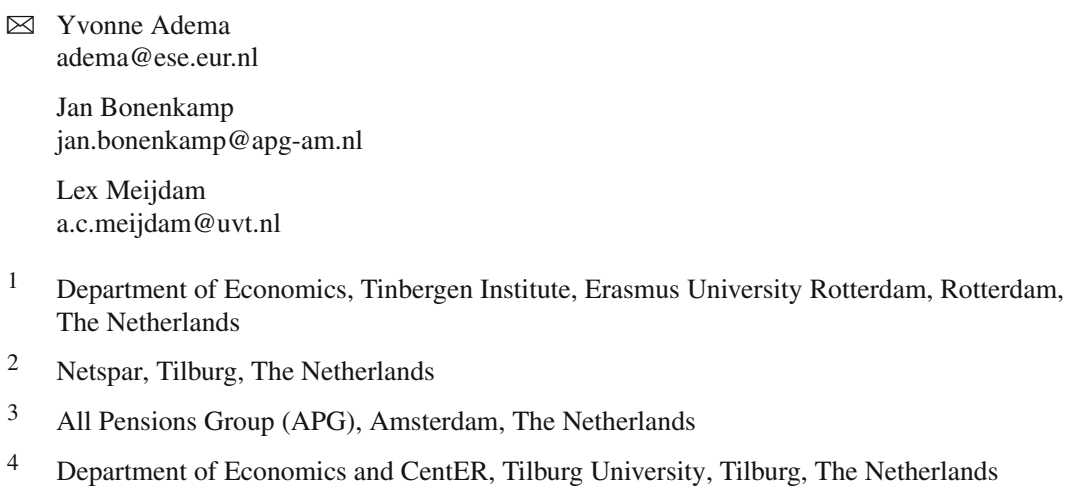




\section{Introduction}

Since the 1970s, the effective retirement age has declined in almost all Western countries, while at the same time life expectancy has increased substantially. These developments led to an increase in the average retirement period relative to the working period, thereby eroding the fiscal sustainability of pension schemes. To reverse this trend, in recent years more attention has been given to pension reforms that improve labour supply incentives and encourage people to work longer. Countries like the UK and Australia, for example, introduced a flexible retirement age and increased the reward to continue working. The advantage of this type of reforms is that it not only reduces the labour market distortions caused by incentives to retire early but can also increase the sustainability of pension systems.

A potential disadvantage is, however, that these flexibility reforms are typically implemented in a uniform way, i.e. applied to all participants in the same way, while individuals have heterogeneous characteristics (e.g., in terms of life expectancy or income level). Uniformly implemented reforms therefore probably have different welfare effects at the individual level and may affect certain types of individuals negatively. ${ }^{1}$ Indeed, it is well known that pension schemes based on uniform policy rules contain large redistribution effects within and across generations, some intentional, and others unintentional (see, e.g. Börsch-Supan and Reil-Held 2001 and Bonenkamp 2009). For example, unfunded pension schemes, especially those of the Beveridgean type, often contain redistribution from high to low incomes. Apart from this, these pension schemes typically also redistribute from short-lived to long-lived agents because they are based on collective annuities which do not depend on individual life expectancy. This makes collective annuities subject to the objection that they lead to more regressive pension schemes because it is well known that average longevity tends to increase with income (see e.g. Pappas et al. 1993; Adams et al. 2003; Meara et al. 2008). Pension reforms that introduce more flexibility in pension take-up will affect these redistribution effects. It is therefore important to take into account the redistribution in existing pension schemes and the fact that individuals are heterogeneous when analysing the welfare effects of pension flexibility reforms.

This paper explores the redistribution and welfare effects of the introduction of a flexible starting date for pension benefits in the context of an unfunded pension scheme with an explicit redistribution motive. That means, we consider a change from a payout scheme in which benefits start at the fixed statutory retirement age to a scheme where benefits start at the flexible effective retirement age. This flexible pension take-up is combined with actuarial adjustments of pension benefits for early or late retirement. To analyse the economic implications of this reform, we use a twoperiod overlapping-generations model populated with agents who differ in ability and lifespan. It is assumed that the lifespan of an individual is positively linked to his productivity. The pay-as-you-go (PAYG) social security system is of the Beveridgean type and is characterized by lifetime annuities and proportional contributions. In this way,

\footnotetext{
1 In the Netherlands, for example, there was a lot of discussion whether a reform aimed at increasing the retirement age would not hurt the low-skilled too much as these people typically start working earlier and have a shorter lifespan and therefore prefer to retire early.
} 
the pension scheme includes two types of intragenerational redistribution, from highincome earners to low-income earners and from short-lived to long-lived agents. Note that, in contrast to the former, the latter type of redistribution is regressive due to the positive link between productivity and longevity. The fact that individuals are heterogeneous implies that introducing pension flexibility will affect individuals differently.

In this paper, we take a positive perspective and observe that in many countries, PAYG pension schemes do redistribute in practice. That is, we follow the literature that takes the existence of a PAYG social security scheme as a redistribution device as given (see e.g. Galasso and Profeta 2002; Cremer and Pestieau 2003; Casamatta et al. 2005). Of course, there are many good reasons for redistributing income via pensions, for example, protection against myopia or the fact that individual differences in income could manifest themselves only later in the career. However, the normative question why pension schemes should be redistributive within cohorts remains outside the scope of this paper.

Implementing pension contracts with a variable starting date for benefits, as analysed in this paper, is important for various reasons. It helps individuals to adjust the timing of pension income according to their own preferences and circumstances. This is particularly relevant for people who have a preference to retire early but who are prevented to do that because of liquidity or borrowing constraints. Flexible pensions can also function as a hedge against all types of risks, like disability risks (Diamond and Mirrlees 1978), stock market risks (Bodie et al. 1992) or productivity risks (Pestieau and Possen 2010). This paper adds some other arguments. We will illustrate that flexible pensions can stimulate people to postpone retirement voluntary. In that case, flexible pension take-up may help to bear the increasing fiscal burden of ageing. We also show that flexible pension take-up could be used to reduce the element of regressive redistribution in social security schemes.

The main results are as follows. First, introducing a flexible pension take-up cannot be Pareto improving if the government conditions the adjustment factor of benefits on individual characteristics like lifespan. Individual actuarial adjustment eliminates the unintended redistribution from short-lived to long-lived agents. The low-skilled therefore benefit from this reform at the expense of the high-skilled. Second, introducing a flexible pension take-up can be Pareto improving if the actuarial adjustment of benefits occurs in a uniform way (i.e. based on the average lifespan). Uniform benefit adjustment leads to selection effects in the retirement decision which may reduce initial tax distortions. For the high-skilled individuals, the uniform reward rate for later retirement is too high from an actuarial point of view because they live longer, which reduces their implicit tax and stimulates them to continue working. If the contribution rate is sufficiently high, the low-skilled also gain because they receive higher pensions, enabled by the additional tax payments of the high-skilled. Third, combining uniform adjustment with actuarial non-neutrality to induce people to postpone retirement can further improve the reform, i.e. a Pareto improvement can be achieved at a lower contribution rate, or for a given contribution rate, the welfare effects are more positive for all individuals.

It is important to note that our benchmark PAYG scheme is of the Beveridgean type and characterized by inflexible pension take-up and lifetime annuities. Countries like the UK, the Netherlands and Denmark indeed follow this tradition. Other countries, 
like Germany, Italy and France have Bismarckian pension schemes where pension benefits are linked to former contributions. In general, Bismarckian pension systems still contain intragenerational redistribution from short- to long-lived agents but have considerably less redistribution from the rich to the poor. As a consequence, with this type of pension scheme, the labour market distortions caused by incentives to retire early, and therefore also the potential for welfare gains of introducing flexible retirement with an increased reward to continue working as studied in this paper, will be much smaller than with a Beveridgean pension system.

This paper is related to studies that analyse the interaction between pension schemes and retirement decisions (see, e.g. Hougaard Jensen et al. 2003) and to a growing literature that focuses on the role of alternative pension systems when income and lifespan are correlated (see, e.g. Borck 2007; Hachon 2008; Cremer et al. 2010). In addition, our paper is also related to Fisher and Keuschnigg (2010) and Jaag et al. (2010) who investigate the labour market impact of pension reforms towards more actuarial neutrality. Most of these aforementioned studies focus on pension reforms that strengthen the link between contributions and benefits. Our study, in contrast, deals with the implementation of a flexible pension take-up.

This paper is most closely related to Cremer and Pestieau (2003). They analyse the implementation of age-dependent tax rates in an economy with a redistributive PAYG pension scheme. This policy generates the same 'double dividend' as the flexibility reform of the pension scheme considered in this study: it not only generates additional revenues but also fosters redistribution from high to low incomes. An important difference with Cremer and Pestieau (2003) is that in our model, people have heterogeneous lifespans. Heterogeneous lifespans play a crucial role in our analysis as this leads endogenously to the 'right' retirement incentives (i.e. the high-skilled will work longer and the low-skilled shorter) when a flexible retirement scheme with uniform actuarial adjustment is introduced. Cremer and Pestieau (2003) need age-dependent taxes to achieve a similar result. The flexible retirement reform we study differs in two important aspects from the introduction of age-dependent taxation. Firstly, in contrast to age-dependent taxation, it is directly targeted at the retirement distortion caused by the PAYG pension scheme. That is, it only affects the retirement decision (i.e. the extensive margin of labour supply), not the decision how many hours to work (the intensive margin). ${ }^{2}$ Secondly, the introduction of flexible pension take-up as considered in this paper is more often observed in practice than age-dependent taxation. ${ }^{3}$

Our main contribution in this respect is that we provide a rationale for the empirically observed introduction of pension flexibility with actuarial adjustment of benefits in a Beveridgean pension scheme. In particular, we elucidate why these pension flexibility reforms are typically implemented in a uniform way instead of making the adjustment of benefits dependent on individual characteristics; we show that the only way to

\footnotetext{
2 The number of hours worked is exogenous in our model. However, the fact that the reform affects only the retirement decision implies that the efficiency improvement that we study can also arise in a more general set-up that also includes the intensive margin (see Fisher and Keuschnigg 2010).

3 One of the reasons why we do not observe age-dependent taxation might be that it is unconstitutional (e.g. because it is seen as discriminatory).
} 
induce a Pareto improvement is by adjusting the benefits in a uniform way, even though individuals are heterogeneous.

This paper is organized as follows. In Sect. 2, we introduce the benchmark model. This model contains a PAYG social security scheme with inflexible pension takeup and lifetime annuities. Section 3 analyses the redistribution and welfare effects of reforms aimed at increasing the flexibility of individual pension take-up. In Sect. 4, we elaborate on these flexibility reforms by introducing non-neutral actuarial adjustment of benefits. Section 5 concludes the paper.

\section{The benchmark model}

We consider a two-period overlapping-generations model of a small open economy populated with heterogeneous agents who differ in terms of ability and lifespan. Agents decide upon the amount of savings in the first period and upon the length of the working period in the second period of life. The individual ability level determines whether an agent supplies labour as a low-skilled worker or as a high-skilled worker. Highskilled workers earn a higher wage rate than low-skilled workers. The model includes a Beveridgean social security scheme which offers a lifetime annuity that starts paying out from the statutory retirement age until the end of life. Agents are allowed to continue their working life after the statutory retirement age or to advance retirement and stop working before the statutory retirement age. So the statutory retirement age is related to the date agents receiving their pension benefit, which is not necessarily equal to their effective retirement date.

\subsection{Preferences}

Preferences over first-period and second-period consumption are represented by the following utility function:

$$
U(c, x)=u(c)+\pi u(x)
$$

with $u^{\prime}>0$ and $u^{\prime \prime}<0$; $c$ is first-period consumption; $x$ is second-period consumption; and $\pi \leq 1$ is the length of the second period. To keep the analysis as simple as possible, we assume that the interest rate and the discount rate are zero. ${ }^{4}$ Second-period consumption is defined net of the disutility of labour:

$$
x=\frac{d}{\pi}-\frac{\gamma}{2}\left(\frac{z}{\pi}\right)^{2}
$$

where $d$ is total consumption of goods when old yielding a consumption stream of $d / \pi, z$ denotes the working period, and $\gamma$ is the preference parameter for leisure.

\footnotetext{
${ }^{4}$ We also abstract from population and productivity growth, which implies that the internal rate of return of the PAYG scheme equals the interest rate so that we can concentrate on the intragenerational redistribution effects of the PAYG scheme. Relaxing these assumptions would not change our main results, however.
} 
Following Casamatta et al. (2005) and Cremer and Pestieau (2003), we assume a quadratic specification for the disutility of work. This specification makes the problem more tractable, but comes with the cost that there are no income effects in labour supply. Income effects in the retirement decision are found to be small compared to substitution effects, however, see, e.g. Krueger and Pischke (1992) or French (2005). Observe that the disutility of working is related to the fraction of the second period spent on working (i.e. $z / \pi$ ). This implies that for a given retirement age, an agent with a short lifespan experiences a higher disutility of work than an agent with a long lifespan because this short-lived agent works a relatively larger share of his remaining lifetime.

\subsection{Innate ability and skill level}

There are two levels of work skill, denoted by 'low' $(L)$ and 'high' $(H)$. Born lowskilled, an agent can acquire extra skills and become a high-skilled worker by investing $1-a$ units of time in schooling in the first period. The rest of the time, $a$, is devoted to working as a high-skilled worker.

The individual-specific parameter $a$ reflects the ability of individuals to acquire high working skills. The higher is $a$, the more able is the individual, and the less time a worker needs to become high-skilled for acquiring a work skill. The parameter $a$ ranges between 0 and 1, and its cumulative distribution function is denoted by $G(\cdot)$, i.e. $G(a)$ is the number of individuals with an innate ability parameter below or equal to $a$. We henceforth refer to an individual with an innate ability parameter of $a$ as an $a$-individual. For the sake of simplicity, we normalize the total number of individuals born in each period to be one, i.e. $G(1)=1$.

A high-skilled worker provides an effective labour supply of one unit per unit of working time, while a low-skilled worker provides only $q<1$ units of effective labour for each unit of working time. This difference in effective labour supply also applies to the second period of life. Let $w$ denote the wage rate per unit of effective labour, then the maximum amount of income agents can earn in the first period, denoted by $W_{y}(a)$, is given by:

$$
W_{y}(a) \equiv\left\{\begin{array}{l}
q w \text { for } a \leq a^{*} \\
a w \text { for } a \geq a^{*}
\end{array}\right.
$$

where $a^{*}$ is the cut-off ability level to become high-skilled. It is assumed that $a^{*}$ is exogenous. ${ }^{5}$ For the second period of life, the maximum labour income, $W_{o}(a)$, equals:

$$
W_{o}(a) \equiv \begin{cases}q w & \text { for } a \leq a^{*} \\ w & \text { for } a \geq a^{*}\end{cases}
$$

\footnotetext{
${ }^{5}$ In the online Appendix C we work out the model with endogenous schooling like in Razin and Sadka (1999). As shown, endogenizing the skill level does not change the main results derived in the body of this paper.
} 


\subsection{Individual lifespan}

Each individual lives completely the first period of life (with a length normalized to unity), but only a fraction $\pi(a) \leq 1$ of the second period. We assume that $\pi^{\prime}(a) \geq 0$ : the higher the innate ability of an agent, the longer the length of life. As a consequence, our model contains a positive association between longevity and skill level. Since highskilled agents earn a higher wage rate than low-skilled workers, the model is in line with the empirical evidence that income positively co-moves with life expectancy. ${ }^{6}$

Whenever necessary to parameterize the function $\pi(a)$, we will use the following specification:

$$
\pi(a)=\bar{\pi}[1+\lambda(a-\bar{a})], \quad \lambda>0
$$

where $\bar{a} \equiv \int_{0}^{1} a \mathrm{~d} G$ denotes the average ability level. This simple function has the following appealing properties. First, $\bar{\pi}$ represents the average duration of the second phase of life. Second, there is a positive link between ability and the length of life as long as $\lambda>0$. Indeed, $\operatorname{Cov}(\pi, a)=\lambda \operatorname{Var}(a) \geq 0$. Third, consistent with empirical findings (Pappas et al. 1993; Mackenbach et al. 2003; Meara et al. 2008), the relative differences in individual lifespans remain constant if the average lifespan increases. In absolute terms, this means that the socioeconomic gap in longevity gets larger if the average life span increases, i.e. $\pi(a=1)-\pi(a=0)=\lambda \bar{\pi}$; the lifespan of more able individuals increases more when average longevity rises.

\subsection{Consumption and retirement}

An individual faces the following intertemporal budget constraint:

$$
c+d=(1-\tau) W_{y}+(1-\tau) z W_{o}+P
$$

where $\tau$ is the social security contribution (tax) rate and $P$ denotes total pension entitlements received during old age. ${ }^{7}$

Maximizing lifetime utility (1) over $c, d$ and $z$, subject to the lifetime budget constraint (6) yields the following first-order conditions:

$$
\begin{aligned}
u^{\prime}(c) & =u^{\prime}(x) \\
(1-\tau) W_{o} & =\frac{\gamma z}{\pi}
\end{aligned}
$$

Expression (7) is the standard consumption Euler equation. Equation (8) is the optimality condition regarding retirement and states that the marginal benefit of working (net wage rate) should be equal to the marginal cost of working (disutility of labour).

\footnotetext{
6 See Adams et al. (2003) for an extensive listing of studies dealing with the association of socioeconomic status and longevity.

7 It is assumed that individual abilities and lifespans are not publicly observable and therefore non-uniform lump-sum transfers are not available.
} 
From these first-order conditions, we obtain the following expressions for $c, x$ and $z$ for the benchmark model:

$$
\begin{aligned}
& c=\frac{1}{1+\pi}\left[(1-\tau) W_{y}+\frac{(1-\tau)^{2} W_{o}^{2} \pi}{2 \gamma}+P\right] \\
& x=c \\
& z=\frac{(1-\tau) W_{o} \pi}{\gamma}
\end{aligned}
$$

where $P$ denotes total pension entitlements in the benchmark model. Note that the social security tax distorts the retirement decision: the larger the contribution rate $\tau$, the earlier agents leave the labour market, i.e. the lower $z$, because it reduces the net wage (and thus the price of leisure). Notice further that our disutility specification ensures that the retirement period is proportional to longevity, i.e. $\pi-z=\left[1-(1-\tau) W_{o} / \gamma\right] \pi$. Hence, a longer lifespan is split between later retirement and a longer retirement period. Low-skilled workers retire earlier than high-skilled workers for two reasons. First, since it is assumed that $q<1$, low-skilled people have a lower wage rate (substitution effect). Second, low-skilled workers will generally have a shorter lifespan which induces them to leave the labour force earlier (disutility of labour effect).

\subsection{Social security}

The PAYG social security scheme is of the Beveridgean type. In the benchmark model, agents receive a flat pension benefit $b$ per retirement period which starts at the statutory retirement age $h$ and lasts until the end of the individual old-age period $\pi$. Total pension entitlements $P$ are then: ${ }^{8}$

$$
P=(\pi-h) b
$$

The fact that the pension benefit is flat but social security contributions $\tau$ are proportional to the wage rate implies that the pension scheme redistributes income from high-income to low-income individuals. The pension scheme also redistributes from short-lived to long-lived individuals, however, as individuals receive the flat pension benefit until their death. The positive link between ability, wages and lifespan in our model then implies that there is also some redistribution from low incomes to high incomes, as the latter group typically has a longer lifespan.

A feasible social security pension scheme must satisfy the following resource constraint: ${ }^{9}$

$$
\int_{0}^{1} P \mathrm{~d} G=\tau q w \int_{0}^{a^{*}}\left(1+z_{L}\right) \mathrm{d} G+\tau w \int_{a^{*}}^{1}\left(a+z_{H}\right) \mathrm{d} G
$$

\footnotetext{
${ }^{8}$ We impose that $\pi-h>0$ for any $a$-individual. In other words, nobody passes away before the statutory retirement age.

9 Throughout this paper, subscript ' $L$ ' refers to low-skilled workers and subscript ' $H$ ' refers to high-skilled workers.
} 
Using Eqs. (5) and (12), we can rewrite this equation as:

$$
b(\bar{\pi}-h)=\tau q w \int_{0}^{a^{*}}\left(1+z_{L}\right) \mathrm{d} G+\tau w \int_{a^{*}}^{1}\left(a+z_{H}\right) \mathrm{d} G
$$

This condition states that the total amount of pension benefits paid out (left-hand side) equals the total amount of tax contributions received (right-hand side). The first term on the right-hand side is the tax payments of the low-skilled workers, and the second term is the payments of the high-skilled workers.

As a measure for redistribution, we calculate the net benefit of participating in the pension scheme. The net benefit is the difference between the total pension benefits received and tax contributions paid:

$$
N B \equiv(\pi-h) b-\tau\left(W_{y}+z W_{o}\right)
$$

An agent is a net beneficiary if total pension benefits received exceed contributions paid (i.e. $N B>0$ ). Otherwise, the agent is a net contributor (i.e. $N B<0$ ). A priori it is not immediately clear whether the low-skilled agents are the net beneficiaries of this Beveridgean pension system. On the one hand, low-skilled agents benefit from this pension scheme as they have a lower wage rate and generally retire earlier than highskilled agents. On the other hand, low-skilled agents also die earlier than high-skilled agents, which implies that low-skilled agents are negatively affected by the pension scheme.

Using the definition of net benefits, Eq. (15), the budget constraint of the pension scheme implies:

$$
\int_{0}^{a^{*}} N B_{L} \mathrm{~d} G+\int_{a^{*}}^{1} N B_{H} \mathrm{~d} G=0
$$

The net benefits of all (young) individuals are equal to zero, reflecting the zero-sum game nature of the pension scheme. ${ }^{10}$

\section{Pension flexibility reforms}

In recent years, many countries have taken measures to increase work incentives and to stimulate people voluntarily to continue working. In this section, we consider the welfare and redistribution effects of a pension reform that allows for a flexible starting date of social security benefits, as recently implemented in e.g. the UK, Finland and Denmark. Introducing a variable starting date for benefits may help individuals to adjust the timing of pension income according to their own preferences. We will show that flexible pensions can also help to bear the costs of ageing or to reduce unintended transfers from short-lived to long-lived individuals.

\footnotetext{
10 With a positive interest rate the sum of net benefits would be negative as in that case, all future generations have to pay for the windfall gain given to the old generation at the time the pension scheme was introduced.
} 
In the benchmark model, we have assumed that social security benefits start at the statutory retirement date, irrespective of the individual's effective retirement date. In this section, we impose that the benefits start at the time the individual actually leaves the labour market. If a person then retires later than the statutory retirement age, he receives an increment to his benefits for later retirement, and when this person retires earlier, he receives a decrement. The imposed coincidence of pension take-up and retirement is a realistic assumption because in practice flexible pension schemes often contain legal restrictions to continue work after a person has opted for benefits. ${ }^{11} \mathrm{We}$ will first discuss the actuarial adjustment of benefits in general. The specific cases of individual actuarial adjustment and uniform actuarial adjustment of benefits will be discussed in Sects. 3.1 and 3.2, respectively.

\section{Actuarial adjustment of benefits}

Suppose the government pays benefits $p$ to an individual over his whole effective retirement period. Total pension entitlements are then equal to $P=(\pi-z) p$. Pension earnings per retirement period $p$ are given by:

$$
p=m(z, \hat{\pi}) b
$$

where $b$ is the reference flat pension benefit independent of contributions and labour history. The factor $m(\cdot)$ is the actuarial adjustment factor which determines to what extent the reference benefit $b$ will be adjusted when agents retire later or earlier than the statutory retirement age and is given by:

$$
m(z, \hat{\pi})=\frac{\bar{\pi}-h}{\hat{\pi}-z}
$$

where we impose $\hat{\pi}-z>0$ to make sure that $m(\cdot)>0$ to rule out negative pension benefits. The adjustment factor is equal to the ratio between the average retirement period and the individual retirement period measured by the reference lifespan parameter $\hat{\pi}$ which will be specified below. At the individual level, actuarial non-neutrality arises when $\hat{\pi}$ differs from $\pi$. The function $m(\cdot)$ is an increasing function in the individual retirement decision $z$; when an agent decides to continue to work after the statutory retirement age, the pension benefit in the remaining retirement periods will be adjusted upwards.

We consider two scenarios for the lifespan to be used in the adjustment factor which differ with respect to the information set available to the government. In the first scenario, the government can observe individual longevity and uses adjustment factors based on individual lifespans $(\hat{\pi}=\pi)$. The government can then get rid of the adverse redistribution from short- to long-lived individuals. The implication of this is, however, that the high-skilled will be harmed by this reform while the low-skilled gain, and a Pareto improvement is not possible. In the second scenario, we assume that

11 In countries like Portugal, Spain and France, the coincidence of pension take-up and retirement is regulated by law. In the Dutch flexible second-pillar schemes, the access to pension benefits is also conditional on dismissal. 
the government applies a uniform actuarial adjustment factor, based on the average lifespan of the population $(\hat{\pi}=\bar{\pi})$. This uniform actuarial adjustment introduces selection effects in the retirement decision, long-lived agents have an incentive to postpone retirement, while short-lived agents have an incentive to advance retirement. We show that in this reform scenario, a Pareto improvement is possible.

\subsection{Individual actuarial adjustment of benefits}

To set the scene, we assume that the government can observe individual lifespans (or individual abilities) ${ }^{12}$ and uses this information to assess the adjustment of benefits. This complete actuarial adjustment is a rather extreme position as it seems quite unrealistic that the government can observe individual lifespans. Moreover, it removes the raison d'être of our pension scheme as a redistribution device. Still, we think it is useful to present this case as a benchmark to demonstrate that it is impossible to generate a Pareto improvement with complete actuarial adjustment of benefits. It illustrates that a degree of incompleteness in the actuarial adjustment is necessary to generate a Pareto improvement, as in the case with uniform actuarial adjustment presented in Sect. 3.2. Moreover, we show in the online Appendix B that the same result applies in the more realistic case where the government cannot observe the individual lifespan, but only the skill level, i.e. the education level (which in general is correlated with individual lifespans, see e.g. van Kippersluis et al. 2011) and uses that information to adjust the benefits; also in that case, actuarial adjustment of benefits cannot result in a Pareto improvement.

\subsubsection{Actuarial adjustment factor}

With individual adjustment, $\hat{\pi}=\pi$, the individual-specific adjustment factor $m$ and the pension entitlements $P$ become:

$$
\begin{aligned}
m & =\frac{\bar{\pi}-h}{\pi-z} \\
P & =(\bar{\pi}-h) b
\end{aligned}
$$

Note from Eq. (19) that $m=1$ for an agent with an average ability level $(a=\bar{a})$ who retires at the statutory retirement age $h$. For this so-called average individual, the pension benefit per retirement period is equal to the reference benefit, i.e. $p=b$. In case this person retires later than the statutory retirement age, then $m>1$, implying that the per-period benefit is adjusted upwards, i.e. $p>b$. On the other hand, when the person retires earlier than the statutory retirement age, we have $m<1$ and $p<b$.

The retirement decision is actuarially neutral because the effective retirement age has no effect on the total pension entitlements $P$, i.e. $\partial P / \partial z=0$. Agents cannot increase their total pension entitlements by postponing or advancing retirement. Any

\footnotetext{
12 Using individual abilities to adjust the benefits gives the same result as using individual lifespans because there is a one-to-one relation between ability and lifespan (see Eq. (5)).
} 
individual, irrespective of lifespan, income or skill level, receives exactly the same amount of lifetime pension benefits.

\subsubsection{Consumption and welfare effects}

The retirement decisions are the same as in the benchmark social security model $\left(z_{\text {ben }}=z_{\text {ind }}\right) .{ }^{13}$ The aggregate budget constraint of the pension contract also does not change, implying that the pension benefit per retirement period stays the same as well $\left(b_{\text {ben }}=b_{\text {ind }}\right)$. Only consumption changes:

$$
\begin{aligned}
& c_{\text {ind }}=c_{\text {ben }}+\frac{(\bar{\pi}-\pi) b}{1+\pi} \\
& x_{\text {ind }}=x_{\text {ben }}+\frac{(\bar{\pi}-\pi) b}{1+\pi}
\end{aligned}
$$

With individual actuarial adjustment, the redistribution in the PAYG scheme related to differences in lifespan (i.e. from short-lived to long-lived agents) that is present in the benchmark model is removed, but the retirement decision is not changed. As a result, lifetime income, and therefore consumption, is higher for short-lived individuals (i.e. with a lifespan $\pi$ below the average lifespan $\bar{\pi}$ ) and vice versa for long-lived individuals $(\pi>\bar{\pi})$. From this, we can immediately infer the following result:

Proposition 1 Introducing retirement flexibility using individual actuarial adjustment of pension benefits implies that the welfare of the short-lived agents $(\pi<\bar{\pi})$ increases while the welfare of the long-lived agents $(\pi>\bar{\pi})$ decreases. This reform therefore cannot be a Pareto improvement.

As the retirement decisions are the same as in the benchmark model, introducing flexible retirement with individual actuarial adjustment does not generate an efficiency gain, only pure redistribution. As a consequence, an improvement according to the Kaldor-Hicks criterion is not possible either.

\subsection{Uniform actuarial adjustment of benefits}

Individual lifespans are difficult to observe in practice. Therefore, real-world pension schemes with a flexible starting date for benefits always rely on uniform actuarial adjustment factors based on some average life expectancy index. In this section, we show that this uniform adjustment of benefits can increase welfare of all individuals, i.e. induce a Pareto improvement, although individuals are heterogeneous.

\footnotetext{
13 In the rest of this paper, subscript 'ben' refers to the benchmark model and subscript 'ind' to the flexible model based on individual actuarial adjustment of benefits. We only use subscripts if it is strictly necessary, i.e. in equations in which we compare one of the flexibility reforms with the benchmark case.
} 


\subsubsection{Actuarial adjustment factor}

With uniform adjustment, the reference lifespan index is the same for each agent, $\hat{\pi}=\bar{\pi}$, so the adjustment factor and pension entitlements are:

$$
\begin{aligned}
& m=\frac{\bar{\pi}-h}{\bar{\pi}-z} \\
& P=\frac{(\pi-z)(\bar{\pi}-h) b}{\bar{\pi}-z}
\end{aligned}
$$

The actuarial adjustment factor $m$ equals one for each individual who retires at the statutory retirement age, i.e. if $z=h$, so that $p=b$. Agents who retire later than $h$ receive a higher benefit, $p>b$, and agents who retire earlier receive less, $p<b$.

From Eq. (24), we observe that, ceteris paribus, total pension entitlements of agents with long lifespans are higher than the entitlements of agents with short lifespans. This redistribution implies that the pension scheme is not actuarially neutral at the individual level. As the amount of pension entitlements depends on the individual retirement age, uniform actuarial adjustment introduces selection effects in the retirement decision. To show this, we derive from Eq. (24):

$$
\Psi(z) \equiv \frac{\partial P(z)}{\partial z}=\frac{(\pi-\bar{\pi}) p}{\bar{\pi}-z}
$$

For agents with above-average lifespans $(\pi>\bar{\pi}), \Psi>0$, implying that these agents have an incentive to postpone retirement as this will increase their lifetime pension income. From an actuarial point of view, the conversion factor of these agents is too high. For short-lived people (with $\pi<\bar{\pi}$ ) it is just the opposite; for these agents, the conversion factor of continued activity is too low which stimulates early retirement. For these people, postponing retirement would simply mean that total pension entitlements decrease $(\Psi<0)$.

\subsubsection{Consumption and retirement}

With flexible pension take-up and uniform actuarial adjustment, the lifetime budget constraint of the $a$-individual is still equal to Eq. (6), but now $P$ is defined as in Eq. (24). Only the first-order condition regarding retirement changes:

$$
(1-\tau) W_{o}+\Psi(z)=\frac{\gamma z}{\pi}
$$

with $\Psi(z)$ given by Eq. (25). Consumption and retirement are then equal to: ${ }^{14}$

$$
c_{u n i}=c_{b e n}+\frac{1}{1+\pi}\left[P_{u n i}-P_{b e n}-\frac{\left[\Psi\left(z_{u n i}\right)\right]^{2} \pi}{2 \gamma}\right]
$$

\footnotetext{
14 Subscript 'uni' refers to uniform actuarial adjustment of benefits.
} 


$$
z_{u n i}=z_{\text {ben }}+\frac{\Psi\left(z_{u n i}\right) \pi}{\gamma}
$$

Equation (28) shows that there is an extra distortion in retirement behaviour. Like before, we have that the contribution rate induces early retirement (through its impact on $z_{\text {ben }}$ ). The redistribution effects, represented by $\Psi$, imply an additional distortion in the retirement decision. This redistribution distortion can either stimulate retirement or depress retirement, depending on the individual lifespan $\pi$. For individuals with below-average lifespans $(\pi<\bar{\pi}), \Psi<0$, which implies that these people retire earlier as a result of uniform actuarial adjustment. If individuals have above-average lifespans $(\pi>\bar{\pi})$, then $\Psi>0$, and these people will postpone retirement.

Consumption can either be higher or lower compared to consumption in the benchmark case. The last term in Eq. (27) is negative and reflects the utility loss resulting from the redistribution distortion in the retirement decision. Of course, flexibility can also induce a utility gain because an agent can choose the retirement age which gives him the highest entitlements. This potential gain is captured by the term $P_{u n i}-P_{\text {ben }}$. Note from Eqs. (12) and (24) that total pension benefits are generally not the same in the benchmark scheme and in the flexibility reform with uniform adjustment. ${ }^{15}$

\subsubsection{Welfare effects}

The welfare effects are not trivial because, compared to the benchmark model, uniform adjustment introduces another distortion in the retirement decision which can work into the opposite direction of the existing distortion related to the contribution tax. We will show that under certain conditions, this reform can lead to a Pareto improvement.

Suppose that the reform takes place unexpectedly. First we will analyse how this reform affects utility of the current old generation. In the benchmark, second-period consumption is equal to:

$$
\pi x_{b e n}=s_{b e n}+\frac{(1-\tau)^{2} W_{o}^{2} \pi}{2 \gamma}+P_{b e n}
$$

where savings are equal to $s=(1-\tau) W_{y}-c$. After the reform, the first-order condition for the retirement decision of the old generation is given by Eq. (26). Using this condition, old-age consumption after the reform is:

$$
\pi x_{\text {uni }}=s_{\text {ben }}+\frac{(1-\tau)^{2} W_{o}^{2} \pi}{2 \gamma}+P_{\text {uni }}-\frac{\left[\Psi\left(z_{\text {uni }}\right)\right]^{2} \pi}{2 \gamma}
$$

The old generation is not worse off after the reform when $u\left(x_{u n i}\right)-u\left(x_{\text {ben }}\right) \geq 0$, implying:

15 This difference is not only due to the direct effect of a different adjustment factor, but also due to the effect of the adjustment factor on the retirement decisions which, via the budget constraint of the PAYG scheme, will in general lead to a different flat reference pension benefit $b$. 


$$
\pi x_{u n i}-\pi x_{b e n} \geq 0 \Rightarrow P_{u n i}-P_{b e n}-\frac{\left[\Psi\left(z_{u n i}\right)\right]^{2} \pi}{2 \gamma} \geq 0
$$

The current young generation and future generations are better off if $U\left(c_{\text {uni }}, x_{\text {uni }}\right) \geq$ $U\left(c_{\text {ben }}, x_{\text {ben }}\right)$ for each ability level, which implies, using Eq. (7), $c_{u n i} \geq c_{\text {ben }}$. From Eq. (27), we can see that the condition for young and future generations is exactly the same as that for the current old generation. This is due to the fact that there are no income effects in the retirement decision. Consequently, for a given ability level, the transition generation and all future young generations retire at the same age and thus have the same amount of lifetime income. Hence, when condition (31) is satisfied and is strictly positive for at least one $a$-individual, the reform is Pareto improving. To analyse the possibility of a Pareto improvement, we make the following assumption:

Assumption 1 The statutory retirement age is set equal to the retirement age of the individual with the average ability level, i.e. $h=z(\bar{a})$.

This assumption implies that individuals with below-average life span have an incentive to advance retirement as from an actuarial point of view the adjustment factor of retirement postponement is too low for them. Therefore, for these people, retiring after the statutory retirement age is not in their interest, ceteris paribus, as it reduces pension entitlements compared to the benchmark. For individuals with above-average life span, exactly the opposite holds. These individuals have an incentive to postpone retirement because the actuarial adjustment factor is too high for them. Hence, retiring before the statutory retirement is not in their interest.

Suppose Assumption 1 is satisfied, we can then derive the following result:

Proposition 2 A pension reform from inflexible Beveridgean pensions towards flexible Beveridgean pensions with the same tax rate and uniform actuarial adjustment of pension benefits is a Pareto improvement if and only if $\tau \geq \tau^{*}$, with $\tau^{*}$ equal to:

$$
\tau^{*}=\frac{(\gamma-q w) \sqrt{\gamma-w}-(\gamma-w) \sqrt{\gamma-q w}}{w \sqrt{\gamma-q w}-q w \sqrt{\gamma-w}}
$$

\section{Proof See Appendix A.1}

The intuition for this result is as follows. High-skilled workers certainly gain from this reform because the adjustment factor is too high for them from an actuarial perspective because they live longer. This leads to a lower implicit tax on continued activity and thus later retirement. The welfare of low-skilled workers in principle declines because they are confronted with higher implicit taxation as their actuarial adjustment factor is too low. The only way to compensate for this loss is to give the low-skilled more social security benefits. If the contribution tax rate is sufficiently high, it is indeed possible that the continued activity of the more able generates enough resources to compensate the less able so that ultimately the welfare of all agents is higher.

Instead of keeping the tax rate constant as assumed in Proposition 2 and making everyone better of, the government may also use the additional resources generated by reducing the distortion of the retirement decision to lower the tax rate without making 


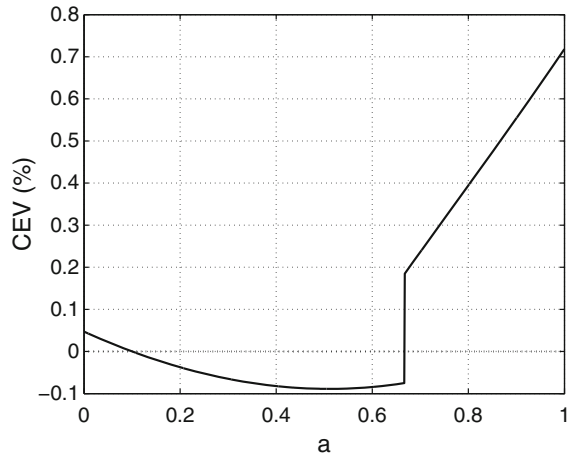

(a)

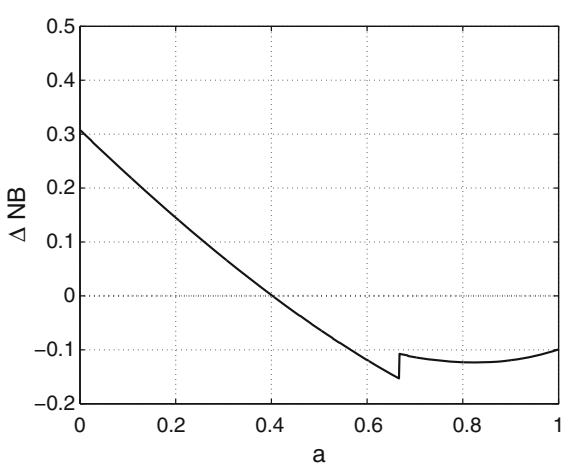

(b)

Fig. 1 Uniform adjustment: welfare and redistribution. a Welfare. b Net benefit. Notes: The welfare effects are measured in terms of consumption equivalent variation: the percentage of extra consumption an agent would require in the benchmark situation to be as well off as after the flexibility reform. The net benefit is the difference between the total pension benefits received and tax contributions paid, see Eq. (15). The graph shows the absolute change in the net benefit from the benchmark

anyone worse of. In this way, introducing flexible retirement with uniform actuarial adjustment can be viewed as a reform to prevent the increasing fiscal burden of ageing. The crucial factor allowing for this is that the reform generates a double dividend: it not only generates additional revenues but also fosters redistribution from high to low incomes. Similar to Cremer and Pestieau (2003), this 'double dividend' hinges on two conditions. First, the retirement decision in the benchmark pension scheme needs to have a downward distortion, i.e. retirement is too early, and the removal of this distortion therefore brings additional resources. Second, the pension contract needs to be redistributive from rich to poor individuals so that most of the cost of the reform is borne by the high-income people. ${ }^{16}$

In Fig. 1, we show a numerical illustration of the welfare (left graph) and redistribution effects (right graph) of a switch to a flexible scheme based on uniform actuarial adjustment. The underlying parameterization is as follows. The tax rate $\tau$ is $0.3,{ }^{17}$

\footnotetext{
16 Instead of assuming a fixed tax rate as in Proposition 2 or an ad hoc decrease in the tax rate, one could also assume a government that optimally sets the tax rate so as to maximize a social welfare function weighing the welfare of the various groups in society. This would not change our result: a Pareto improvement results if the initial optimal tax rate is sufficiently high. The intuition for this is that, as stated in the proposition, the introduction of flexible retirement with uniform actuarial adjustment with a given tax rate leads to a welfare gain that allows for a Pareto improvement. If an optimizing government adjusts the tax rate jointly with the introduction of flexible retirement, this will affect the allocation of this welfare gain, but a welfare maximizing government will always allocate the welfare gain in such a way that no group is worse off compared to the initial situation.

17 This might seem a rather high number for a tax rate primarily used for old-age pensions. However, in reality redistribution from high to low incomes also occurs in other parts of the economy, like the tax and public health care system. What is crucial for our results is not so much the exact level of the tax for the pension scheme as such, but the distortion determined by the marginal tax rate that results from all redistributive taxes together. The contribution rate for the Dutch Beveridgean pension scheme (the AOW) is currently $17.9 \%$. And if we take the contribution rates for the other national insurance schemes (mainly insurance against special health care expenditures) into account, the contribution rate is $31.15 \%$.
} 
$w=1$ and $\gamma=2$. We further assume $h=1 / 6$ and $\bar{\pi}=0.7$, which implies an official retirement age of 65 and an average lifespan of 81 years. ${ }^{18}$ The heterogeneity parameter $\lambda$ is calibrated such that the difference between the lifespan of high-skilled and low-skilled agents is at most 3.5 years which is consistent with recent Dutch estimates, this gives $\lambda=1 / 6$. We interpret the high skill level as the highest attainable education levels in the Netherlands (i.e. higher vocational training and university) and the low skill level as the collective term of all remaining education levels. According to recent figures of Statistics Netherlands, about two-third of the Dutch population is low-skilled $\left(a^{*}=2 / 3\right)$ and these people earn about $40 \%$ less than high-skilled agents $(q=0.6)$. Finally, we assume that ability $a$ follows a uniform distribution, ${ }^{19}$ i.e. $G(a)=a$, and that the utility function is logarithmic, i.e. $u(\cdot)=\ln (\cdot)$.

Figure 1a shows that the welfare effects of introducing flexible retirement with uniform adjustment are positive for all high-ability agents. These agents benefit from a lower implicit tax on continued activity due to the attractive actuarial adjustment factor and therefore choose to work longer. With these parameter settings, however, the additional tax contributions are not sufficient to compensate all lowskilled agents for the higher implicit tax they are confronted with, although most of them experience an increase in the net benefit from the scheme (see Fig. 1b). To achieve a Pareto improvement, the contribution rate needs to be at least $40 \%$, that is, $\tau^{*}=0.4$.

There are good reasons to argue that in practice the tax critical rate is lower than presumed in our analysis. First, as explained in Footnote 17, income redistribution from rich to poor runs through more channels than the pension scheme, like the tax system or public health care. Hence, when high-skilled agents are stimulated to work longer with a flexible pension take-up, the low-skilled may also be compensated through these other types of redistribution. Second, in reality the contribution tax is added to other sources of distortionary taxation. As the deadweight loss is roughly quadratic in the total tax rate, the marginal welfare improvement of introducing flexible retirement (and lowering implicit taxation) might be larger than our analysis suggests. In the next section, we show that a reduction in the tax critical rate can also be obtained by reformulating the pension reform to some extent, i.e. by setting the reward rate of retirement postponement above the actuarially neutral level.

\section{Footnote 17 continued}

Moreover, the marginal tax rate is about $50 \%$ for most Dutch citizens (see CPB 2012). Therefore we think that assuming a tax rate of $30 \%$ is not so unrealistic.

18 We assume that lifetime consists of 30 years of childhood that are not accounted for, 30 years of full potential working time (which can partly be used for tertiary education) and a last period of 30 years. The official retirement age is therefore $60+30 h$ and the average lifespan is $60+30 \bar{\pi}$. The average lifespan at birth of 81 years is taken from the online population projection 2012-2060 of Statistics Netherlands (statline.cbs.nl).

19 The assumption of a uniform distribution used in the example is not crucial for our results. Other distributions will lead to the same results, provided that the mass of high-skilled individuals in the distribution is sufficiently large. This is important as the extra tax revenues generated by this group should be sufficiently large to compensate the low-skilled. 


\section{Introducing actuarial non-neutrality}

In recent years, an increasing number of countries introduced penalties and rewards for earlier and later retirement. To stimulate work continuation, the penalty rate is typically not as high as the reward rate, i.e. the adjustment is asymmetric. In the USA, for example, for each year of retirement before the statutory retirement age, the annual benefit is reduced by $6.75 \%$. The actuarial increment for those retiring after the statutory retirement age amounts to $8 \%$. In Japan, the difference is even larger, where the penalty rate of early retirement is $6 \%$ per year while the reward rate of later retirement is $8.4 \%$ (OECD 2011). In this final section, we therefore consider a pension flexibility reform where pension benefits are adjusted in an actuarially nonneutral way to induce people to postpone retirement. We show that under such a reform, a Pareto improvement can be achieved at a lower contribution rate or that for a given contribution rate, it leads to more positive welfare effects for all individuals.

\subsection{Actuarial adjustment factor}

To make our point as clear as possible, we abstract from lifespan heterogeneity in the analytical analysis. Hence, each agent, irrespective of his ability level, lives a fraction $\pi \leq 1$ of the second period. In the simulation graphs, however, we have heterogeneous lifespans. The actuarial adjustment factor is specified as follows:

$$
m(z, \pi)=\left(\frac{\pi-h}{\pi-z}\right)^{\sigma}, \quad \sigma \geq 1
$$

where the parameter $\sigma$ governs the degree of actuarial non-neutrality of the adjustment factor, this is also shown in Fig. 2. In case $\sigma=1$, the adjustment is completely actuarially neutral with respect to the retirement decision (see Sect. 3.1). For $\sigma>1$, the adjustment factor is higher than the actuarially neutral level if agents retire later

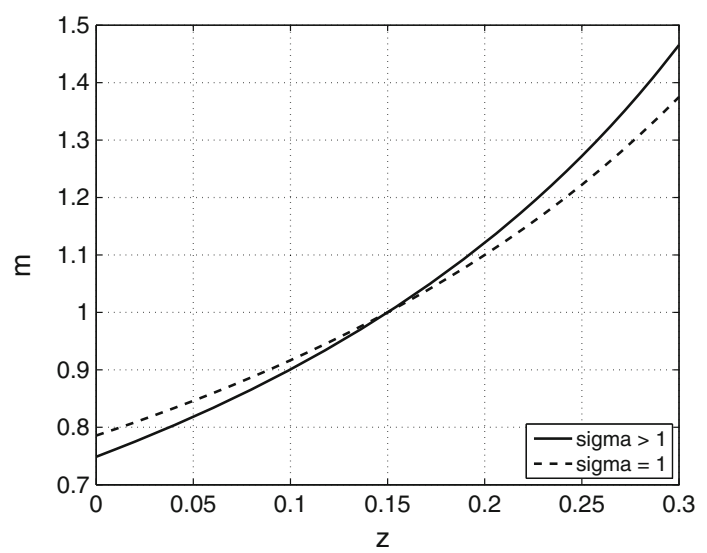

Fig. 2 Actuarial adjustment factor 
than the statutory retirement age $(z>h)$. On the contrary, the adjustment factor is lower than the actuarially neutral level if agents retire earlier than the statutory retirement age $(z<h)$. In other words, specification (33) rewards delaying retirement and discourages early retirement as long as $\sigma>1$.

Given Eq. (33), the pension entitlements $P$ are equal to:

$$
P=(\pi-h)^{\sigma}(\pi-z)^{1-\sigma} b
$$

Taking the derivative of $P$ with respect to $z$ gives:

$$
\Psi(z) \equiv \frac{\partial P(z)}{\partial z}=(\sigma-1) p
$$

Hence, if $\sigma>1$ then $\Psi>0$, i.e. introducing actuarial non-neutrality gives all agents an incentive to continue working as this will increase pension entitlements.

\subsection{Consumption and retirement}

The consumption decision and retirement decision are equal to: ${ }^{20}$

$$
\begin{aligned}
& c_{\text {nan }}=c_{\text {ben }}+\frac{1}{1+\pi}\left[P_{\text {nan }}-P_{\text {ben }}-\frac{\left[\Psi\left(z_{\text {nan }}\right)\right]^{2} \pi}{2 \gamma}\right] \\
& z_{\text {nan }}=z_{\text {ben }}+\frac{\Psi\left(z_{\text {nan }}\right) \pi}{\gamma}
\end{aligned}
$$

where $P$ and $\Psi$ are defined by Eqs. (34) and (35), respectively. Taking the derivative of the retirement choice with respect to the parameter $\sigma$ that governs the degree of actuarial non-neutrality gives (evaluated at $\sigma=1$ ):

$$
\left.\frac{\partial z}{\partial \sigma}\right|_{\sigma=1}=\frac{\pi p}{\gamma}>0
$$

An increase in the parameter $\sigma$ (starting from actuarial neutrality, i.e. $\sigma=1$ ) leads to later retirement. The introduction of this kind of non-neutrality in the retirement decision can undo (at least to some extent) the distortionary effect of the social security tax. This result is comparable with the situation in the flexibility reform with uniform actuarial adjustment and heterogeneous lifespans. With uniform actuarial adjustment, however, the pension scheme is still actuarially neutral on average: high-skilled workers (with a long lifespan) receive a subsidy on continuing work, whereas low-skilled workers (with a short lifespan) experience a tax on delaying retirement. The current reform is different because now the pension scheme subsidizes work continuation for all agents, irrespective of skill level.

$\overline{20}$ Subscript 'nan' refers to non actuarially-neutral adjustment of benefits. 


\subsection{Welfare effects}

Introducing actuarial non-neutrality does not only stimulate labour supply, it also leads to a Pareto improvement if the tax rate is sufficiently high.

Proposition 3 With a given tax rate, introducing actuarial non-neutrality aimed at stimulating work effort makes high-skilled workers strictly better off. In addition, the reform is Pareto improving if and only if $\tau>\hat{\tau}$, with:

$$
\hat{\tau}=\frac{\left[1-G\left(a^{*}\right)\right] \ln \left(\frac{\pi-z_{L}}{\pi-z_{H}}\right)}{G\left(a^{*}\right) \frac{q w \pi}{\gamma\left(\pi-z_{L}\right)}+\left[1-G\left(a^{*}\right)\right] \frac{w \pi}{\gamma\left(\pi-z_{H}\right)}}
$$

This implicit equation has a unique solution.

\section{Proof See Appendix A.2}

The intuition for this result is similar as in the reform with uniform actuarial adjustment (see Sect. 3.2). The government can apply non-neutral actuarial conversion of benefits for late retirement as an instrument to increase the total efficiency of the economy. This subsidy reduces the existing labour supply distortion on the retirement decision related to the contribution tax rate. With actuarial non-neutrality, however, the reward rate of retirement postponement is relatively more attractive for agents who retire later (i.e. the high-skilled), as can also be seen from Fig. 2. Therefore, to ensure that the welfare of the low-skilled also improves, the contribution rate needs to be sufficiently high so that the additional tax payments of the high-skilled lead to higher pension benefits.

Figure 3 compares the welfare effects of a uniform adjustment under actuarial neutrality (dashed line) and actuarial non-neutrality (solid line). Contrary to the analytical exposition discussed above, this graph is based on heterogeneous lifespans (see also Eq. (5)). All parameter values are the same as those used in the previous graphs. As we

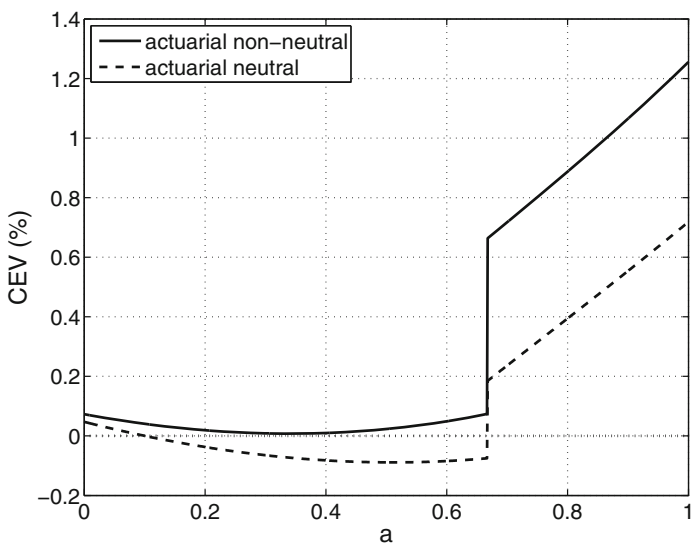

Fig. 3 Neutral versus non-neutral actuarial adjustment. Notes: The welfare effects are measured in terms of consumption equivalent variation: the percentage of extra consumption an agent would require in the benchmark situation to be as well off as after the flexibility reform. The actuarially non-neutral scenario is based on $\sigma=1.05$ 
have shown before, a contribution rate of $30 \%$ is not sufficient to ensure that an actuarially neutral and a uniform adjustment of benefits is Pareto improving. Figure 3 shows, however, that when a uniform adjustment is combined with actuarial non-neutrality, this has strictly positive welfare effects for all individuals under a contribution rate of $30 \%$, i.e. the reform is Pareto improving. This implies that by introducing actuarial non-neutrality in the pension scheme, it is possible to achieve a Pareto improvement for a lower contribution tax rate. The reason for this result is that an actuarial nonneutral uniform adjustment gives more incentives for the high-skilled to retire later and that their labour supply in the second period will be higher than under the actuarially neutral reform; this will generate more resources to compensate the low-skilled.

\section{Conclusion}

In this paper, we have studied the intragenerational redistribution and welfare effects of a pension reform that introduces a flexible take-up of pension benefits. To analyse the economic implications of such a pension reform, we have developed a stylized two-period overlapping-generations model populated with heterogeneous agents who differ in ability and lifespan. The model includes a Beveridgean social security scheme with lifetime annuities. In this way, we take into account the empirically most important channels of intragenerational redistribution: income redistribution from rich to poor people and lifespan redistribution from short-lived to long-lived agents.

Our results suggest that introducing a flexible pension take-up with uniform adjustments can induce a Pareto improvement. This reform can collect additional resources without diminishing the welfare of low-skilled agents and increasing that of highskilled agents. In that way, it can also help to bear the costs of ageing in a Beveridgean pension scheme. The selection effects of uniform actuarial adjustment increase the implicit tax of the low-skilled, but decrease the implicit tax of the high-skilled, who in turn decide to work longer and therefore pay more pension contributions. A necessary condition for such a Pareto improvement is that the contribution tax is sufficiently high so that the continued activity of the high-skilled generates enough tax revenues to compensate the low-skilled with higher benefits. Increasing the reward and penalty rates of later and earlier retirement in an actuarially non-neutral way can help to reduce this tax critical rate. This policy reduces the implicit tax not only of the high-skilled agents but also of the low-skilled, implying that the less-skilled agents need less compensation through the redistributive pension scheme.

In real-world pension schemes that have actuarial adjustment of pension entitlements, this adjustment is indeed independent of individual characteristics, like life expectancy or skill level. The results of this paper give a rationale for this kind of uniform flexibility reforms. In recent years, penalties and rewards for earlier or later retirement have increased in a number of countries (OECD 2011). However, in most countries, the implemented reductions in early pension benefits do still not fully correspond both to the lower amount of contributions paid by the worker and to the increase in the period over which the worker will receive pension payments (Queisser and Whitehouse 2006). This implies that there is still room to improve the pension systems by going into the direction of complete actuarial neutrality or by moving even beyond that level, as our analysis of non-actuarial neutral adjustment suggests. 
Other important elements to which we have not paid attention, but that might be important when analysing pension flexibility, are the role of income effects in the retirement decision or social norms. Especially in the short run, flexibility in the pension age could lead to only small changes in retirement behaviour if agents are used to retire at some socially accepted retirement age. In the long run, however, norms may change and the effects described in this paper may still apply. To what extent these kinds of issues would affect our main results is left for future research.

Our paper, however, provides a rationale why countries with Beveridgean pension schemes should use uniform rules for the adjustment of pension benefits when they introduce flexible pension take-up even though people have different skill levels and life expectancies. It is sometimes argued that it would be preferable to base the actuarial adjustment factor on individual life expectancy or skill level. This paper shows that even in a very simple setting, the latter type of pension flexibility reform cannot be Pareto improving as some of the redistribution in the initial pension scheme (from the short- to the long-lived) is removed. It is therefore important to take all types of redistribution in the initial pension scheme into account when discussing the implementation of flexible pension take-up. Applying uniform actuarial adjustment, possibly combined with non-neutral elements to increase the incentives to postpone retirement, could increase the economic efficiency of the pension system. In that way, this reform generates extra resources to cope with the costs of ageing and makes some people better off while not hurting other people.

Acknowledgments We are grateful to two anonymous referees, Casper van Ewijk, Kees Goudswaard, Ben Heijdra and Ed Westerhout for their comments on earlier versions of this paper. We also wish to thank the participants of the pension workshop in Wuerzburg (June 5, 2012), the participants of the Netspar International Pension Workshop in Paris (June 7, 2012) and the participants of the Annual Congress of the International Institute of Public Finance in Dresden (August 16, 2012) for helpful comments and suggestions.

Open Access This article is distributed under the terms of the Creative Commons Attribution License which permits any use, distribution, and reproduction in any medium, provided the original author(s) and the source are credited.

\section{Appendix}

This appendix contains formal proofs of all propositions mentioned in this paper.

\section{Proofs}

Proof of Proposition 2

Proof We have the following condition for a Pareto improvement:

$$
\begin{aligned}
\Gamma & \equiv P_{\text {uni }}-P_{\text {ben }}-\frac{[\Psi(z)]^{2} \pi}{2 \gamma} \\
& =\frac{(\pi-z)(\bar{\pi}-h)}{\bar{\pi}-z} b_{u n i}-(\pi-h) b_{\text {ben }}-\frac{[\Psi(z)]^{2} \pi}{2 \gamma} \geq 0
\end{aligned}
$$


where for at least one $a$-individual, this inequality has to hold strictly. To avoid complex analytical expressions that yield no additional insights, we evaluate all derivatives in the proofs at the initial point $\lambda=0$, i.e. starting from a situation where each agent has the same lifespan. In the simulation graphs presented in the main text, we allow for lifespan heterogeneity, however. Setting $\lambda=0$ means that $\pi(a)=\bar{\pi}$ for each $a$-individual and hence $\Gamma=0$. Now we derive the following derivative at $\lambda=0$ :

$$
\frac{\partial \Gamma}{\partial \lambda}=\frac{z-h}{\bar{\pi}-z} \bar{\pi}(a-\bar{a}) b_{u n i}+(\bar{\pi}-h)\left(\frac{\partial b_{u n i}}{\partial \lambda}-\frac{\partial b_{b e n}}{\partial \lambda}\right)
$$

To prove that the reform is Pareto improving, we have to show that $\partial \Gamma / \partial \lambda \geq 0$, and for at least one individual, it should be strictly positive. Note that Assumption 1 implies that the minimum of the first term is equal to zero, i.e. for the agent with ability $a=\bar{a}$. Hence, the reform is Pareto improving if $\partial b_{u n i} / \partial \lambda \geq \partial b_{b e n} / \partial \lambda$.

The budget constraint of the pension scheme can be written as:

$$
b(\bar{\pi}-h) \Phi=X
$$

with:

$$
\begin{aligned}
& \Phi \equiv \int_{0}^{a^{*}}\left[\frac{\pi-z_{L}}{\bar{\pi}-z_{L}}-\frac{(\pi-\bar{\pi}) \tau q w \pi}{\gamma\left(\bar{\pi}-z_{L}\right)^{2}}\right] \mathrm{d} G+\int_{a^{*}}^{1}\left[\frac{\pi-z_{H}}{\bar{\pi}-z_{H}}-\frac{(\pi-\bar{\pi}) \tau w \pi}{\gamma\left(\bar{\pi}-z_{H}\right)^{2}}\right] \mathrm{d} G \\
& X \equiv \tau q w \int_{0}^{a^{*}}\left[1+\frac{(1-\tau) q w \pi}{\gamma}\right] \mathrm{d} G+\tau w \int_{a^{*}}^{1}\left[a+\frac{(1-\tau) w \pi}{\gamma}\right] \mathrm{d} G
\end{aligned}
$$

Note that in the benchmark model $\Phi=1$. From Eq. (42), we derive at $\lambda=0$ :

$$
\begin{aligned}
\frac{\partial b_{\text {ben }}}{\partial \lambda} & =\frac{1}{\bar{\pi}-h} \frac{\partial X}{\partial \lambda} \\
\frac{\partial b_{u n i}}{\partial \lambda} & =\frac{1}{\bar{\pi}-h}\left(\frac{\partial X}{\partial \lambda}-X \frac{\partial \Phi}{\partial \lambda}\right)
\end{aligned}
$$

Hence,

$$
\frac{\partial b_{u n i}}{\partial \lambda}-\frac{\partial b_{b e n}}{\partial \lambda}=-\frac{X}{\bar{\pi}-h} \frac{\partial \Phi}{\partial \lambda}
$$

From the definition of $\Phi$ above and applying Leibniz rule, we obtain:

$$
\begin{aligned}
\frac{\partial \Phi}{\partial \lambda}= & \frac{\bar{\pi}}{\bar{\pi}-z_{L}}\left[1-\frac{\tau q w \bar{\pi}}{\gamma\left(\bar{\pi}-z_{L}\right)}\right] \int_{0}^{a^{*}}(a-\bar{a}) \mathrm{d} G \\
& +\frac{\bar{\pi}}{\bar{\pi}-z_{H}}\left[1-\frac{\tau w \bar{\pi}}{\gamma\left(\bar{\pi}-z_{H}\right)}\right] \int_{a^{*}}^{1}(a-\bar{a}) \mathrm{d} G
\end{aligned}
$$


Inserting Eq. (28) with $\lambda=0$ in this expression, gives:

$$
\frac{\partial \Phi}{\partial \lambda}=\underbrace{\frac{\gamma(\gamma-q w)}{(\gamma-q w+\tau q w)^{2}}}_{\Pi_{L}} \int_{0}^{a^{*}}(a-\bar{a}) \mathrm{d} G+\underbrace{\frac{\gamma(\gamma-w)}{(\gamma-w+\tau w)^{2}}}_{\Pi_{H}} \int_{a^{*}}^{1}(a-\bar{a}) \mathrm{d} G
$$

Let $\tau \rightarrow 0$. Then we have that $\Pi_{H}>\Pi_{L}$ which implies that the derivative is positive and thus $\partial b_{u n i} / \partial \lambda<\partial b_{\text {ben }} / \partial \lambda$ for any possible cut-off point $0<a^{*}<1$. Taking the other extreme, $\tau \rightarrow 1$, we obtain $\Pi_{H}<\Pi_{L}$ so that the derivative is negative and $\partial b_{\text {uni }} / \partial \lambda>\partial b_{\text {ben }} / \partial \lambda$ for any value $0<a^{*}<1$. The derivative is zero if and only if $\Pi_{H}\left(\tau^{*}\right)=\Pi_{L}\left(\tau^{*}\right)$ which has a unique solution $0<\tau^{*}<1$ given by Eq. (32). Hence, $\partial b_{\text {uni }} / \partial \lambda \geq \partial b_{\text {ben }} / \partial \lambda$ if and only if $\tau \geq \tau^{*}$. This completes the proof.

\section{Proof of Proposition 3}

Proof With actuarial non-neutrality, the Pareto improving condition is: ${ }^{21}$

$$
\Gamma \equiv(\pi-h)^{\sigma}(\pi-z)^{1-\sigma} b_{\text {nan }}-(\pi-h) b_{b e n}-\frac{[\Psi(z)]^{2} \pi}{2 \gamma} \geq 0
$$

where for at least one $a$-individual, this inequality should hold strictly. Suppose we start from a situation of actuarial neutrality, $\sigma=1$, which means $\Gamma=0$. Then we derive the following derivative, evaluated in the initial position $\sigma=1$ :

$$
\frac{\partial \Gamma}{\partial \sigma}=(\pi-h) \frac{\partial b}{\partial \sigma}+(\pi-h) b \ln (\pi-h)-(\pi-h) b \ln (\pi-z)
$$

To prove that the reform is Pareto improving, we have to show that $\partial \Gamma / \partial \sigma \geq 0$, where for at least one individual, this inequality strictly holds.

Write the budget constraint of the pension scheme in the usual way:

$$
b(\pi-h) \Phi=X
$$

where $X$ is already defined by Eq. (44) and with $\Phi$ equal to:

$$
\begin{aligned}
\Phi \equiv & G\left(a^{*}\right)\left[\left(\frac{\pi-z_{L}}{\pi-h}\right)^{1-\sigma}-\frac{\tau q w \pi(\sigma-1)(\pi-h)^{\sigma-1}}{\gamma\left(\pi-z_{L}\right)^{\sigma}}\right] \\
& +\left[1-G\left(a^{*}\right)\right]\left[\left(\frac{\pi-z_{H}}{\pi-h}\right)^{1-\sigma}-\frac{\tau w \pi(\sigma-1)(\pi-h)^{\sigma-1}}{\gamma\left(\pi-z_{H}\right)^{\sigma}}\right]
\end{aligned}
$$

\footnotetext{
21 As before, we abstract from lifespan heterogeneity, i.e. $\lambda=0$, in this section. The simulation graph presented in the main text is based on heterogeneous lifespans, however.
} 
Note that $\Phi=1$ if $\sigma=1$, implying that Eq. (51) can be written as:

$$
\frac{\partial \Gamma}{\partial \sigma}=(\pi-h) \frac{\partial b}{\partial \sigma}+X \ln (\pi-h)-X \ln (\pi-z)
$$

From Eq. (52), it follows:

$$
\frac{\partial b}{\partial \sigma}=-\frac{X}{\pi-h} \frac{\partial \Phi}{\partial \sigma}
$$

Using definition (53), we can derive at $\sigma=1$ :

$$
\begin{aligned}
\frac{\partial \Phi}{\partial \sigma}= & \ln (\pi-h)-G\left(a^{*}\right)\left[\ln \left(\pi-z_{L}\right)+\frac{\tau q w \pi}{\gamma\left(\pi-z_{L}\right)}\right] \\
& -\left[1-G\left(a^{*}\right)\right]\left[\ln \left(\pi-z_{H}\right)+\frac{\tau w \pi}{\gamma\left(\pi-z_{H}\right)}\right]
\end{aligned}
$$

Substituting Eq. (56) into Eq. (55) and inserting the resulting expression in Eq. (51) ultimately imply:

$$
\begin{aligned}
\frac{\partial \Gamma}{\partial \sigma}= & -X \ln (\pi-z)+G\left(a^{*}\right) X\left[\ln \left(\pi-z_{L}\right)+\frac{\tau q w \pi}{\gamma\left(\pi-z_{L}\right)}\right] \\
& +\left[1-G\left(a^{*}\right)\right] X\left[\ln \left(\pi-z_{H}\right)+\frac{\tau w \pi}{\gamma\left(\pi-z_{H}\right)}\right]
\end{aligned}
$$

For high-skilled agents, we have $z=z_{H}$, implying:

$$
\begin{aligned}
\frac{\partial \Gamma}{\partial \sigma}= & G\left(a^{*}\right) \frac{\tau q w \pi X}{\gamma\left(\pi-z_{L}\right)}+\left[1-G\left(a^{*}\right)\right] \frac{\tau w \pi X}{\gamma\left(\pi-z_{H}\right)} \\
& +G\left(a^{*}\right) X \ln \left(\frac{\pi-z_{L}}{\pi-z_{H}}\right)>0
\end{aligned}
$$

Hence, high-skilled workers are strictly better off when moving from the benchmark scheme to a scheme with actuarial non-neutrality. For the low-skilled agents, we have $z=z_{L}$, which gives:

$$
\begin{aligned}
\frac{\partial \Gamma}{\partial \sigma}= & G\left(a^{*}\right) \frac{\tau q w \pi X}{\gamma\left(\pi-z_{L}\right)}+\left[1-G\left(a^{*}\right)\right] \frac{\tau w \pi X}{\gamma\left(\pi-z_{H}\right)} \\
& -\left[1-G\left(a^{*}\right)\right] X \ln \left(\frac{\pi-z_{L}}{\pi-z_{H}}\right)
\end{aligned}
$$

Suppose that $\tau \rightarrow 0$. Then $\partial \Gamma / \partial \sigma<0$, implying that low-skilled agents are worse off after the reform. If on the other hand $\tau \rightarrow 1$, then $z_{L}=z_{H}=0$ so that the last term vanishes. Therefore $\partial \Gamma / \partial \sigma>0$ which means that low-skilled also benefit from the reform. We have $\partial \Gamma / \partial \sigma=0$ if $\tau=\hat{\tau}$, with $\hat{\tau}$ given by Eq. (39). 
To prove that $\hat{\tau}$ is a unique solution, we have to show that the derivative $\partial \Gamma / \partial \sigma$ is monotonically increasing in $\tau$ at $\sigma=1$. Rewrite Eq. (59) in $\partial \Gamma / \partial \sigma=X A$, with $A$ equal to:

$$
A \equiv G\left(a^{*}\right) \frac{\tau q w \pi}{\gamma\left(\pi-z_{L}\right)}+\left[1-G\left(a^{*}\right)\right] \frac{\tau w \pi}{\gamma\left(\pi-z_{H}\right)}-\left[1-G\left(a^{*}\right)\right] \ln \left(\frac{\pi-z_{L}}{\pi-z_{H}}\right)
$$

Since $X>0$ the necessary and sufficient condition for $\partial \Gamma / \partial \sigma \geq 0$ is $A \geq 0$. This implies that $\hat{\tau}$ is a unique solution if and only if $A$ is monotonically increasing in $\tau$. Taking the derivative of $A$ with respect to $\tau$ gives, after some algebraic manipulations: ${ }^{22}$

$$
\begin{aligned}
\frac{\partial A}{\partial \tau}= & G\left(a^{*}\right) \frac{q w(\gamma-q w)}{(\gamma-q w+\tau q w)^{2}}+\left[1-G\left(a^{*}\right)\right] \frac{w(\gamma-w)}{(\gamma-w+\tau w)^{2}} \\
& +\left[1-G\left(a^{*}\right)\right] \frac{w \pi}{\gamma}\left(\frac{1}{\pi-z_{H}}-\frac{q}{\pi-z_{L}}\right)>0
\end{aligned}
$$

This completes the proof.

\section{References}

Adams, P., Hurd, M., McFadden, D., Merrill, A., \& Ribeiro, T. (2003). Healthy, wealthy, and wise? Tests for direct causal paths between health and socioeconomic status. Journal of Econometrics, 112, 3-56.

Bodie, Z., Merton, R., \& Samuelson, W. (1992). Labor supply flexibility and portfolio choice in a life cycle model. Journal of Economic Dynamics and Control, 16, 427-449.

Bonenkamp, J. (2009). Measuring lifetime redistribution in Dutch occupational pensions. De Economist, $157,49-77$.

Borck, R. (2007). On the choice of public pensions when income and life expectancy are correlated. Journal of Public Economic Theory, 9, 711-725.

Börsch-Supan, A., \& Reil-Held, A. (2001). How much is transfer and how much is insurance in a pay-asyou-go system? The German case. Scandinavian Journal of Economics, 103, 505-524.

Casamatta, G., Cremer, H., \& Pestieau, P. (2005). Voting on pensions with endogenous retirement age. International Tax and Public Finance, 12, 7-28.

CPB. (2012). Effecten van het regeerakkoord voor de marginale druk. CPB notitie, CPB Netherlands Bureau for Economic Policy Analysis, The Hague (in Dutch).

Cremer, H., Lozachmeur, J.-M., \& Pestieau, P. (2010). Collective annuities and redistribution. Journal of Public Economic Theory, 12, 23-41.

Cremer, H., \& Pestieau, P. (2003). The double dividend of postponing retirement. International Tax and Public Finance, 10, 419-434.

Diamond, P., \& Mirrlees, J. (1978). A model of social insurance with variable retirement. Journal of Public Economics, 10, 295-336.

Fisher, W., \& Keuschnigg, C. (2010). Pension reform and labor market incentives. Journal of Population Economics, 23, 769-803.

French, E. (2005). The effects of health, wealth, and wages on labour supply and retirement behaviour. Review of Economic Studies, 72, 395-427.

Galasso, V., \& Profeta, P. (2002). The political economy of social security: A survey. European Journal of Political Economy, 18, 1-29.

\footnotetext{
22 Note that we assume $\gamma>w$ to make sure that $z<1$ for all agents irrespective the size of the pension scheme (so $\forall \tau$ ).
} 
Hachon, C. (2008). Redistribution, pension systems and capital accumulation. Financial Theory and Practice, 32, 339-368.

Hougaard Jensen, S., Lau, M., \& Poutvaara, P. (2003). Efficiency and equity aspects of alternative social security rules. Finanz Archiv, 60, 325-358.

Jaag, C., Keuschnigg, C., \& Keuschnigg, M. (2010). Pension reform, retirement, and life-cycle unemployment. International Tax and Public Finance, 17, 556-585.

Krueger, A., \& Pischke, S. (1992). The effects of social security on labor supply: A cohort analysis of the notch generation. Journal of Labor Economics, 10, 412-437.

Mackenbach, J., Bos, V., Andersen, O., Cardano, M., Costa, G., Harding, S., et al. (2003). Widening socioeconomic inequalities in mortality in six Western European countries. International Journal of Epidemiology, 32, 830-837.

Meara, E. R., Richards, S., \& Cutler, D. M. (2008). The gap gets bigger: Changes in mortality and life expectancy, by education, 1981-2000. Health Affairs, 27, 350-360.

OECD. (2011). Pensions at a glance: retirement-income systems in OECD and G20 countries. Paris: OECD Publishing.

Pappas, G., Queen, S., Hadden, W., \& Fisher, G. (1993). The increasing disparity in mortality rates between socioeconomic groups in the United States: 1960 and 1986. New England Journal of Medicine, 329, 103-109.

Pestieau, P., \& Possen, U. (2010). Retirement as a hedge. Mimeo.

Queisser, M., \& Whitehouse, E. (2006). Neutral or fair? Actuarial concepts and pension-system design. Mimeo.

Razin, A., \& Sadka, E. (1999). Migration and pension with international capital mobility. Journal of Public Economics, 74, 141-150.

van Kippersluis, H., O’Donnell, O., \& van Doorslaer, E. (2011). Long run returns to education: Does schooling lead to an extended old age? Journal of Human Resources, 46(4), 695-721. 